\title{
The effect of changing presentation and management on the outcome of blunt rupture of the thoracic aorta
}

Judy Cook, MD, ${ }^{a}$ Christopher Salerno, MD, ${ }^{\mathrm{b}}$ Bia Krishnadasan, MD, ${ }^{\mathrm{b}}$ Stephen Nicholls, MD, ${ }^{\mathrm{a}, \mathrm{c}}$ Mark Meissner, MD, ${ }^{\mathrm{a}, \mathrm{c}}$ and Riyad Karmy-Jones, MD ${ }^{\mathrm{b}, \mathrm{c}}$

From the Divisions of Vascular Surgery, ${ }^{\text {a }}$ Cardiothoracic Surgery, ${ }^{\mathrm{b}}$ and Interventional Radiology, ${ }^{\mathrm{c}}$ Harborview Medical Center and the University of Washington, Seattle, Wash.

Received for publication June 21, 2005; revisions received Sept 23, 2005; accepted for publication Oct 20, 2005.

Address for reprints: Riyad Karmy-Jones, MD, Department of Surgery, Box 359796, Harborview Medical Center, 325 Ninth Ave, Seattle, WA 98104 (E-mail: karmy@ u.washington.edu)

J Thorac Cardiovasc Surg 2006;131:594-600 $0022-5223 / \$ 32.00$

Copyright $\odot 2006$ by The American Association for Thoracic Surgery

doi:10.1016/j.jtcvs.2005.10.030
Background: The management of traumatic aortic rupture has evolved from emergency surgery for all to incorporating nonoperative and endovascular approaches. In addition, the greater emphasis on restraint systems over the past decade might result in lower immediate mortality.

Methods: We reviewed our contemporary experience with reference to a previous report from the same institution to determine whether there has been improvement in outcome related to these factors.

Results: In 1990, a review of 104 patients admitted to our center over a 15-year period (1975-1990) noted an overall mortality of 65\%. Forty-two patients died before they could reach the operating room, including 15 who were declared dead on arrival and 27 who died before reaching the operating room. All patients underwent angiography, followed by immediate operation. The mortality rate of those who reached the operating room was $34 \%$, and paralysis-paraplegia occurred in $26 \%$ of survivors. A review of 53 patients admitted between January 1, 2000, and April 2005 documented an overall mortality of $26 \%$ and a paralysis rate of $4.5 \%$ in operative survivors. Only 3 patients died during initial evaluation, 2 who were in arrest on arrival. Eight patients were managed nonoperatively, and 13 were managed by means of deliberate delay before intervention to improve physiologic status. Finally, 19 patients were managed with endografts.

Conclusion: The improved outcome over the decade since the initial experience reflects both a reduced severity of injury attributable to restraint systems and a more flexible approach to the acute management, which can modify the effect of associated injuries.

I n 1990, Eddy and associates ${ }^{1}$ reviewed the outcomes of 104 patients admitted to Harborview Medical Center with the diagnosis of acute rupture of the descending thoracic aorta over a 15-year period (January 1975-August 1989). The cornerstone of management included aggressive angiography to define the injury, followed by emergency operative repair in all cases. As a follow-up, the same group reviewed their experience with mechanical circulatory support and argued that its use was associated with a reduction in paralysis and other end-organ ischemic complications. ${ }^{2}$ The use of heparin-bonded circuits has reduced further the perceived risk of anticoagulation associated with mechanical circulatory support in these settings. ${ }^{3}$ Since that report and stimulated by further research by the same authors and other centers, it has become apparent that a number of significant changes have occurred in this paradigm. In addition, there has been an increased use of restraint devices (air bags and seat belts) that appears to have decreased the incidence of aortic rupture and possibly decreased the severity of associated injuries. ${ }^{4,5}$ Although the majority of patients with aortic rupture still die at the scene, those admitted with signs of life are now categorized as "unstable" (perhaps one 


\section{Abbreviation \\ $\mathrm{CT}=$ computed tomography}

third of those admitted), in whom mortality still remains nearly $100 \%$, and the remainder who are categorized as "stable" and can undergo temporizing medical management with $\beta$-blockers if needed and in whom the mortality, which is as low as $25 \%$, is determined primarily by associated injuries. ${ }^{6-8}$ Furthermore, endograft technology has become increasingly available, offering an alternative to thoracotomy with a further reduction in the risk of paralysis. Finally, since the mid to late 1990s, the concept that all aortic injuries mandate immediate operative repair has given way to a more measured approach that takes into account the possibility in selected patients that delayed intervention might result in improved outcomes. ${ }^{9}$ Since 1998, we have incorporated many of these facets into a more flexible management scheme, although urgent operative repair remains the cornerstone of our approach. Some of the patients discussed formed the basis of earlier reports detailing management of pediatric aortic rupture, the natural history of nonoperative management, the role of left-heart bypass and associated injuries on outcome, and more specific information regarding technical aspects of endovascular stent graft approaches. ${ }^{10-14}$ This article represents an effort to assess, in a global fashion, how the aforementioned changes in therapy and patient population has affected outcome by using the earlier report by Eddy and associates ${ }^{1}$ as a frame of reference.

\section{Material and Methods}

Patients admitted to Harborview Medical Center with the diagnosis of blunt thoracic aortic rupture between January 1, 2000, and April 1, 2005, were entered prospectively into a database. Data included injury severity score, presenting systolic blood pressure, associated injuries, mechanism of injury, time to operation from admission, and outcome, including death, paralysis, or both. Patients who presented with a systolic blood pressure of less than 90 $\mathrm{mm} \mathrm{Hg}$ or whose pressure decreased to less than $90 \mathrm{~mm} \mathrm{Hg}$ after admission and required volume resuscitation or inotropic support were considered unstable. Urgent repair was defined as an operation of any sort within 24 hours of injury. As a practical matter, all urgent operations were performed within 8 hours of injury.

During the initial time period, management included urgent angiography in all patients suspected of having the diagnosis followed by immediate operation, unless there existed a more critical injury with priority. Currently, patients who present with abnormal mediastinum, as determined by means of chest radiography, undergo computed tomographic (CT) angiography, including 3-dimensional reconstruction. Patients in whom there is a concern for pelvic or other bleeding undergo standard angiography. All stable patients are started on $\beta$-blockers when the diagnosis is suggested by chest radiography until the diagnosis is excluded or repair is performed. Transesophageal echocardiography is used when the diagnosis is in question. When comorbidities are deemed to make immediate repair ill-advised, patients are maintained on $\beta$-blockade and followed with serial helical CT angiography performed every 48 to 72 hours until either the patient can withstand repair or the lesion has been unchanged for at least 7 days. The target pressure is less than the admission blood pressure, usually aiming for a systolic blood pressure of between 120 and $130 \mathrm{~mm} \mathrm{Hg}$ but recognizing that some older patients have a higher baseline pressure.

Early in our experience, when delay (either on admission or after a period of nonoperative management) was judged to be associated with risk of impending rupture (caused by enlarging lesion, evidence of psuedocoarcation, and/or large hemothorax) but the risk of open repair was prohibitive, endovascular approaches were considered. Currently, we consider all patients to be candidates for endograft approaches if the anatomy is suitable. ${ }^{11}$

The presence of cardiac risk factors, closed head injury, and pulmonary injury was and is currently determined by criteria similar to those previously reported by other investigators. ${ }^{15}$ Our current practice deviates only in the respect that patients with evidence of increased intracranial pressure are believed to be immediate operative candidates if other factors permit it to prevent secondary brain injury associated with a decrease in cerebral perfusion pressure that accompanies hypotensive medical therapy. In the majority of cases, intracranial pressure monitoring is used to measure and follow cerebral perfusion pressure. Cardiac risk factors were defined by the presence of one or more of the following: echocardiographic, visual, or both types of operative description of segmental ventricular wall motion abnormalities; necessity for inotropic support; increased troponin I levels; or ongoing treatment of angina pectoris. Closed head injury was determined by an abnormal head CT scan (hemorrhage or edema), increased intracranial pressure, or a low Glasgow Coma Score. Pulmonary injury was defined as pulmonary contusion identified on chest imaging with one or more of the following: $\mathrm{PaO}_{2} /$ fraction of inspired oxygen of less than $300 \mathrm{~mm} \mathrm{Hg}$, inability to tolerate single-lung ventilation, or positive end-expiratory pressure requirements of 7.5 $\mathrm{cm} \mathrm{H}_{2} \mathrm{O}$ or greater to maintain satisfactory oxygenation. Coagulopathy was defined by one or more of the following: extensive nonsurgical bleeding, international normalized ratio of greater than 1.5 , or laboratory evidence of consumption (increased fibrin split products and platelet count of $<100,000$ ). Paralysis was determined in those patients who survived long enough for a complete neurologic evaluation.

Injuries with $1 \mathrm{~cm}$ of the left subclavian artery were defined anatomically as involving the ligamentum arteriousm region of the descending thoracic aorta. Injuries that extended or involved the distal arch but were amenable to control through a left posterolateral thoracotomy were also included in this group. Injuries distal to the origin of the innominate artery but proximal to this aforementioned distal arch region were categorized as arch injuries.

Comparison among the groups for survival and paralysis were assessed by using the $t$ test with SSPS 11.5 for Windows.

Outcomes during this contemporary era (Time 2) were compared with those of a previously reported population admitted to Harborview Medical Center between January 1975 and August 1989 (Time 1). $^{1}$ 
TABLE 1. Mechanism of injury and related mortality

\begin{tabular}{lcc}
\hline Mechanism & $\begin{array}{c}\mathbf{1 9 7 5 - 2 0 0 0 ,} \\
\text { n (\% mortality) }\end{array}$ & $\begin{array}{c}\mathbf{2 0 0 0 - 2 0 0 5 ,} \\
\text { n (\% mortality) }\end{array}$ \\
\hline Motor vehicle crash & $74(52)$ & $32(22)$ \\
Vehicle-pedestrian & $8(87.5)$ & $9(22)$ \\
Fall & $4(50)$ & $4(25)$ \\
Motorcycle & $18(67)$ & $7(43)$ \\
Airplane & & $1(100)$ \\
\hline
\end{tabular}

\section{Results}

There was a similar pattern of mechanism between the 2 groups, with an increased propensity for injuries distal to the area of the ligamentum in Time 2 (Tables 1 and 2). During Time 1, the median age was 31 years, and $81 \%$ were male. During Time 2, the average age was $41 \pm 20$ years, and $75 \%$ were male. Of note, of the patients who presented after a motor vehicle crash during Time 1, in only one case was there any evidence of restraint systems being involved. This is significantly different from Time 2 , in which 25 (78\%) of the motor vehicle crash victims had the benefit of air bags, seat belts, or both. Indirect evidence of the benefit of restraint systems can be noted by the marked number of open cardiac ruptures and great vessel injuries noted in Time 1 compared with Time 2, as well as the greater mortality (Table 3). ${ }^{4,5}$ Three (43\%) of 7 unrestrained motor vehicle crash victims during Time 2 died, as opposed to 4 (16\%) of 25 restrained victims. In addition, of the unrestrained victims, 4 had minimal aortic injuries and were successfully managed nonoperatively, whereas all 7 patients who presented with near or total transaction were unrestrained.

There was a much greater reliance on CT angiography during Time 2, with 5 of 8 cases diagnosed by means of angiography performed during embolization of pelvic injuries, solid organ injuries, or both (Table 4).

During Time 1, 50\% of patients were unstable, with $97 \%$ mortality; all deaths were attributed to aortic rupture; and the vast majority of deaths were in the emergency department (ED; Table 3). The diagnosis was confirmed by the

TABLE 2. Anatomic location of injury site and associated mortality

\begin{tabular}{|c|c|c|c|c|}
\hline \multirow[b]{2}{*}{ Location } & \multicolumn{2}{|c|}{$1975-1990$} & \multicolumn{2}{|c|}{ 2000-2005 } \\
\hline & n (\%) & Mortality & n (\%) & Mortality \\
\hline Ascending aorta & 0 & & 1 & 0 \\
\hline Aortic arch & $7(7)$ & $5(81)$ & $3(5.7)$ & $1(33)$ \\
\hline $\begin{array}{l}\text { Ligamentum } \\
\text { arteriosum }\end{array}$ & $93(87)$ & $51(55)$ & $29(54.7)$ & $10(32)$ \\
\hline $\begin{array}{l}\text { Descending thoracic } \\
\text { aorta }\end{array}$ & $6(6)$ & $5(84)$ & $20(37.7)$ & $3(15)$ \\
\hline Multiple sites & $2(2)$ & $2(100)$ & 0 & \\
\hline
\end{tabular}

TABLE 3. Incidence of associated injuries and related mortality

\begin{tabular}{lccllc}
\hline & \multicolumn{2}{c}{$1975-1990$} & & \multicolumn{2}{c}{ 2000-2005 } \\
\cline { 2 - 3 } \cline { 5 - 6 } & $\mathbf{n}(\%)$ & Mortality & & $\mathbf{n}(\%)$ & Mortality \\
\hline Open cardiac injury & $11(11)$ & $11(100)$ & & 0 & - \\
Blunt cardiac injury & $19(18)$ & $14(74)$ & & $12(22.6)$ & $6(50)$ \\
Great vessel injury & $6(6)$ & $5(83)$ & & 0 & - \\
Carotid dissection & 0 & - & & 2 & 0 \\
Closed head injury & $52(50)$ & $35(67)$ & & $27(50.9)$ & $12(45)$ \\
Spine injury & $15(14)$ & $11(73)$ & & $16(30.2)$ & $5(32)$ \\
Pulmonary injury & $55(53)$ & $30(55)$ & & $26(49.6)$ & $11(42)$ \\
Abdominal injury & $59(57)$ & $46(78)$ & & $24(45.3)$ & $5(21)$ \\
Pelvic fracture & $25(24)$ & $16(64)$ & & $24(45.3)$ & $7(29)$ \\
Long bone fracture & $53(51)$ & $30(57)$ & & $27(50.9)$ & $6(22)$ \\
\hline
\end{tabular}

medical examiner. During Time 2, $41 \%$ of patients were unstable, with 50\% mortality. Two patients died in the ED, one who underwent ED thoracotomy and the other who experienced rupture during transport and was declared dead on arrival. Both were transfers from outlying institutions and had the diagnosis confirmed by CT scan before referral. One patient arrested during attempts at pelvic embolization and underwent resuscitative thoracotomy (during which the aorta was found not to have freely ruptured), and a fourth was admitted with the diagnosis of fatal head injury and was declared brain dead after a period of observation in the intensive care unit. Four patients underwent urgent open repair, with 2 dying, both from cardiac failure. Four patients underwent emergency endovascular stent grafting, with all surviving the procedure, but 3 ultimately died from the consequences of closed head injury, multiple organ failure, and cardiogenic shock, respectively. One patient went urgently to the operating suite with the plan of performing an endograft but repeatedly arrested, underwent immediate open thoracotomy, underwent grafting, and died in the operating room because of persistent cardiogenic shock. Nine patients underwent delayed intervention to allow stabilization of associated injuries, 2 who subsequently underwent open repair (both survived) and 7 who underwent endovascular repair, with the sole death being caused by closed head injury.

Of the hemodynamically stable patients in Time 1, all underwent angiography. One patient died of aortic rupture before operative repair could be performed, 7 died intraoperatively, and 4 died postoperatively, with the predominant cause being closed head injury in this latter group. Thus the overall mortality in stable patients was $23 \%$. During Time 2 , 6 stable patients with minimal aortic injury were managed nonoperatively, all of who survived and all of whose injuries have resolved on follow-up. Fifteen patients underwent urgent open repair, with 2 postoperative deaths, one caused by pulmonary embolism (in a patient with severe closed 
TABLE 4. Comparison between the 2 groups on the basis of outcome and presentation

\begin{tabular}{|c|c|c|}
\hline & 1975-1990, n = 104 & 2000-2005, n = 53 \\
\hline Overall mortality & $\begin{array}{l}63(65 \%) \\
\text { - Died in ED without thoracotomy, } n=15 \\
\text { - Died after ED thoracotomy, } n=26 \\
\text { - Died periangiography, } n=11 \\
\text { - Died in OR, } n=7 \\
\text { - Died postoperatively, } n=4\end{array}$ & $\begin{array}{l}14(26 \%) \\
\text { - Died in ED without thoracotomy, } \mathrm{n}=1 \\
\text { - Died after EDT, } \mathrm{n}=1 \\
\text { - Died periangiography, } \mathrm{n}=1 \\
\text { - Died in ICU-supportive care, } \mathrm{n}=1 \\
\text { - Died in OR, } \mathrm{n}=3 \\
\text { - Died postoperatively, } \mathrm{n}=7\end{array}$ \\
\hline Cause of death & $\begin{array}{l}\text { - Free aortic rupture, } \mathrm{n}=52 \\
\text { - Intraoperative hemorrhage from aorta } \\
\text { and extrathoracic, } \mathrm{n}=7 \\
\text { - Closed head injury } \pm \text { multiple organ } \\
\text { failure, } \mathrm{n}=4\end{array}$ & $\begin{array}{l}\text { - Cardiogenic shock, } \mathrm{n}=4 \\
\text { - Closed head injury, } \mathrm{n}=3 \\
\text { - Free aortic rupture, } \mathrm{n}=2 \\
\text { - Extrathoracic hemorrhage, } \mathrm{n}=1 \\
\text { - Pulmonary embolism, } \mathrm{n}=1 \\
\text { - ARDS, } \mathrm{n}=1 \\
\text { - Multiple organ failure, } \mathrm{n}=1 \\
\text { - Postoperative suture dehiscence, } \mathrm{n}=1\end{array}$ \\
\hline Nonoperative cases & 0 & 8 (2 deaths $=25 \%)$ \\
\hline Delayed intervention & 0 & $13(2$ deaths $=15 \%)$ \\
\hline Diagnosis & $\begin{array}{l}\text { - At thoracotomy or postmortem, } 52(50 \%) \\
\text { - Angiography, } 52(50 \%)\end{array}$ & $\begin{array}{l}\text { - At angiography or postmortem, } 1(1.9 \%) \\
\text { - Angiography, } 8(15.1 \%) \\
\text { - CT angiography, } 44(83 \%)\end{array}$ \\
\hline Unstable & $\begin{array}{l}52(50 \%) \\
\text { - Mortality = } 51(97 \%)\end{array}$ & $\begin{array}{l}22(41 \%) \\
\text { - Mortality = } 11(50 \%)\end{array}$ \\
\hline Operative mortality* & Overall $=11 / 53(21 \%)$ & Overall $=12 / 45(26 \%)$ \\
\hline $\begin{array}{l}\text { Paralysis-paraparesis after open } \\
\text { operative repairt }\end{array}$ & $11 / 45(24 \%)$ & $1 / 23(4 \%)$ \\
\hline
\end{tabular}

$E D$, Emergency department; $O R$, operating room; $E D T$, emergency department thoracotomy; $I C U$, intensive care unit; $A R D S$, adult respiratory distress syndrome; $C T$, computed tomography. *Excluding non-survivors of EDT. †Including those who died but a neurologic evaluation was possible and excluding one patient in the latter time period who was paralyzed on admission.

head injury) and the other caused by myocardial infarction in an elderly patient with evidence of closed cardiac injury and severe coronary artery disease. Urgent endografting was used in 6 cases, all of whom were survivors. Delayed operative repair was used in 2 cases, with 1 patient dying 3 weeks postoperatively from complications related to necrotizing pneumonia and suture line dehiscence. Two patients underwent delayed endograft placement, including one who had undergone an attempt at urgent open repair but experienced cardiogenic shock, with the procedure being aborted. Both survived. Thus in Time 2 the overall mortality among stable patients was $10 \%$.

A significant difference between the 2 time periods was the use of specific delay in patients with recognized injuries to allow optimization or resuscitation before intervention during the contemporary period. Thirteen $(25 \%)$ of the patients were managed with interval open or endovascular repair, with the average delay being $7.9 \pm 9.1$ days. The indications for delay were multifactorial and included the following: severe pulmonary contusion $(n=7)$, severe coagulopathy $(\mathrm{n}=5)$, obtaining an endograft that would be sufficient for the specific anatomy $(\mathrm{n}=3)$, need for resuscitation after laparotomy $(\mathrm{n}=2)$, and initial diagnosis of atlanto-occipital dislocation believed to be fatal but with subsequent recovery $(\mathrm{n}=1)$. All patients were candidates for hypotensive therapy, and none died of aortic rupture. As noted previously, the overall mortality in this subgroup was $15 \%(\mathrm{n}=2)$.

Of 45 patients who survived open repair during Time 1, $26(57 \%)$ underwent clamp-and-sew procedures, with the remainder undergoing Gott aortic-aortic shunt $(\mathrm{n}=8)$, left-heart bypass with circulatory support $(\mathrm{n}=8)$, full cardiopulmonary bypass $(n=2)$, and left ventricle-distal aortic shunt $(\mathrm{n}=1)$. Five patients underwent primary repair, 4 with a patch and the remainder with graft interposition. Overall, 11 (24\%) experienced paralysis or paraplegia, whereas renal failure occurred in $3(7 \%)$. The authors did not note a benefit to mechanical circulatory support. As noted previously, the overall perioperative mortality was $24 \%(\mathrm{n}=11)$. Of the 23 patients who underwent open repair (urgent or delayed) during Time 2 (excluding 3 cases of emergency thoracotomy in the $\mathrm{ED}$, in the angiography suite, and caused by persistent cardiac arrest in the operating room during attempted endograft placement), 2 were managed with clamp-and-sew procedures, 17 with left-heart bypass, 3 with the clamshell approach and dual ascending 
TABLE 5. Crossclamp time

\begin{tabular}{lllr}
\hline & $<30$ min & 30-45 min & $>$ 45 min \\
\hline $1975-1990(n=45)$ & $9(20 \%)$ & $15(33 \%)$ & $21(47 \%)$ \\
$2000-2005(n=23)$ & $2(7 \%)$ & $16(70 \%)$ & $5(23 \%)$ \\
\hline
\end{tabular}

aortic and femoral cannulation for arch injuries, and 1 with circulatory arrest for an ascending aortic injury managed initially medically. All but one (primary repair) underwent graft interposition. One of the patients managed with a clamp-and-sew procedure was preoperatively recognized to have had traumatic spinal cord injury. Excluding this patient, all survived long enough to have a neurologic examination, and in only $1(5 \%)$ patient did paralysis occur postoperatively. This was in a patient who presented in shock and underwent reconstruction with left-heart bypass. The crossclamp time was 31 minutes in this case. There were no instances of renal failure. The overall perioperative mortality of open repair among the 24 patients (excluding the 2 cases of preoperative thoracotomy) was 3 in the operating room and 3 postoperatively (25\%). The average crossclamp time during Time 2 was $39.4 \pm 12.7$ minutes, but relatively more patients were in the midrange group (30-45 minutes) than were noted in Time 1 (Table 5).

In the contemporary period a total of 19 endografts were used: Gore (W.L. Gore, Flagstaff, Ariz) cuff extenders (n = 11); Aneurex (Medtronic Corp, Minneapolis, Minn) cuff extenders $(\mathrm{n}=3)$; and 1 each of Ancure (Guidant Corp, Menlo Park, Calif) graft, constructed device (first of the series), contralateral limb of a Gore AAA graft, Gore TAG device, and a Talent (World Medical Manufacturing Corp, Sunrise, Fla) graft, respectively. None of these endografts were placed as part of a trial but rather after compassionate use guidelines. The indications included patients with psuedoaneurysms, anatomy that was believed to be suitable, and 1 or more of the following: pulmonary or cardiac risk factors that prohibited open repair or evidence of malperfusion or decreased cerebral perfusion that contraindicated hypotensive therapy. Access was achieved through the femoral artery in 9 cases, the iliac artery in 7 cases, and the infrarenal aorta in cases. In no case was the orifice of the left subclavian artery occluded, and there were no endoleaks. As noted, $4(21 \%)$ patients ultimately died, but in all operative survivors there was no paralysis and no renal failure. This outcome was not significantly different from that seen in patients who underwent open repair attributable to the significant associated injuries in both groups (injury severity score: $34.5 \pm 9.9$ [operative group] vs $38.9 \pm 10$ [endograft group]; $P=.1$ ).

Summarizing the overall outcomes and comparing all patients from both time periods, there was a reduction in overall mortality from Time $1(63 / 104$ [65\%]) to Time 2 $(14 / 53$ [26\%]). Excluding patients who presented in arrest or who were deemed to have nonsurvivable injuries, the mortality during Time 1 was $35 \%$ (22/63), and that during Time 2 was $20 \%(10 / 50 ; P=.08)$. The overall paralysisparaplegia rate decreased from the aforementioned $24 \%$ in Time 1 to $2 \%$ (1/49; including nonoperative, endovascular, and open repair cases; $P=.001)$ and $2.4 \%(1 / 41$; excluding nonoperative cases; $P=.003$ ).

\section{Discussion}

The management of traumatic rupture of the thoracic aorta has evolved significantly since Parmley and colleagues' 1958 article. ${ }^{16}$ It is now recognized that there are roughly 3 categories of patients: those who die at the scene (70\%-80\% of the whole), those who present in unstable condition or become unstable (2\%-5\% of the whole, with mortality of 90\%-98\%), and those who are hemodynamically stable and are given diagnoses 4 to 18 hours after injury $(15 \%-25 \%$ of the whole, with mortality of $25 \%$ largely caused by associated injuries). ${ }^{6,17}$ This has allowed a more flexible approach, selective operative repair, nonoperative repair, and the emergence of endovascular techniques. These have been assisted by the recognition that early institution of blood pressure control with $\beta$-blockers can markedly reduce the risk of free rupture ${ }^{8,18}$ Over the past decade, there have been a number of potential beneficial changes at out institution, including increased use of restraint systems, perhaps resulting in less severe injuries; use of early $\beta$-blockers in stable patients; less reliance on angiography; selective operative management to allow temporization of associated injuries; increased use of mechanical circulatory support; and increasing experience with endovascular techniques. We have compared our most contemporary 5-year experience with one reported a decade earlier in an attempt to elucidate whether these global changes, noted and advocated by several institutions, have resulted in a significant change in management and outcome at our own institution. Unfortunately, our ability to get exact information regarding patients before approximately mid-1985 is limited, and thus we are unable to perform a more rigorous analysis, but the primary goal was to assess whether there have been global changes in presentation and outcome.

The most common mechanism still remains motor vehicle crashes. ${ }^{19,20}$ Seat belts have been credited with a reduction in fatalities caused by aortic injury. ${ }^{20}$ The lack of seat belt use might result in greater force, perhaps reflected by the increased incidence of ascending aortic rupture found at autopsy in those without seat belts (53.5\%) compared with that seen in those with seat belts $(39.2 \%){ }^{4,5}$ Frontal air bags might be protective in terms of frontal impact, although they can be associated with cardiac and aortic injury, particularly if seat belts are not also worn, and do not protect from side impacts. $^{21,22}$ Although circumstantial, the benefit of restraints might be reflected by the decreased severity of 
associated injuries, notably frank cardiac rupture, as well as a reduction in the incidence of ascending, arch, and multiple tears when comparing the 2 time periods. ${ }^{4,5}$

The primary diagnostic mode remains the documentation of mediastinal hematoma by means of chest radiography. ${ }^{23}$ Once the diagnosis is suspect, the institution of careful blood pressure control while awaiting definitive diagnosis and treatment significantly reduces the risk of rupture. ${ }^{8}$ There was a marked reduction overall in preoperative rupture, leading to death during work up between Time 1 compared with Time 2, which suggests that this approach had some benefit. The ideal target systolic pressure has been quoted as less than $120 \mathrm{~mm} \mathrm{Hg}$ or even $100 \mathrm{~mm} \mathrm{Hg}$, but more recently, aiming for a pressure "lower than initial admission pressure" has been suggested as a more reasonable goal. ${ }^{6}$ There is still debate about whether angiography or CT angiography should be the first test. Dedicated CT angiography appears to have the sensitivity and specificity of angiography, and in addition, 3-dimensional reconstruction techniques can be very useful in planning operative or interventional approaches and might be used to detect smaller lesions. ${ }^{8,24,25}$ Currently, CT angiography might not be reliable to exclude small injuries at the root or proximal great vessels. ${ }^{26-28}$ Our current protocol is to perform angiography if there are associated pelvic injuries suggesting the need for embolization but to perform CT angiography in stable patients. If hematoma is noted to encircle the ascending or arch of the aorta or the great vessels, angiography is performed.

The actual operative technique has undergone minor change. There is increased awareness of the need to control the aorta proximal to the left subclavian artery for injuries that are close to avoid clamping across unrecognized proximal extensions of the injury or second injuries. ${ }^{9}$ In addition, injuries that are within $1 \mathrm{~cm}$ of the origin of the left subclavian artery pose particular risk of rupture during proximal dissection, and thus if mechanical circulatory support is to be used, having it in place before this dissection can be beneficial. ${ }^{12}$ Primary repair, when feasible, is associated with reduced crossclamp times and perhaps improved outcomes, although in our experience we have used it in unstable patients who are in shock most often. ${ }^{29,30} \mathrm{~A}$ more significant change has been the emphasis on the role of bypass in preventing end-organ ischemia and heart failure. Prompted by their initial review of the 1975 through 2000 time period, the same Harborview team re-evaluated the effect of bypass in managing aortic rupture. They noted, over 42 patients, a reduced paralysis rate and renal failure using bypass ( $44 \%$ with clamp-and-sew procedure vs none with bypass), as well as a reduction in pulmonary, gastrointestinal, and septic complications. ${ }^{2}$ Of interest, the total mortality was decreased to $29 \%$. This led to a fundamental change in practice at our own institution. Our own experience suggests that maintaining distal perfusion does mark- edly reduce the incidence of paralysis and that restoring perfusion to the left subclavian artery as soon as possible if more proximal control is required during the clamp-and-sew procedure is beneficial but that the major determining factor is preoperative hypotension. ${ }^{13,14}$ Bypass is currently usually performed with heparinized circuits with inferior pulmonary vein-distal aortic bypass. The use of heparin-bonded circuits reduces the risk of systemic heparinization. ${ }^{3}$

A significant change has been the recognition that selectively delaying operative intervention can be beneficial. ${ }^{6,15,31,32}$ This takes into account the current thought that the 25\% mortality among stable patients is more often due to complications arising from associated injuries. ${ }^{6}$ Combining 4 reviews published between 1992 and 2000, 74 (43\%) of 174 were managed with deliberate temporization, ranging from 1 day to several months. ${ }^{15,32-34}$ There were a total of $4(5 \%)$ free ruptures, all occurring within 72 hours. The cornerstone of this approach is continuous blood pressure control. ${ }^{6,35}$ Patients who do not have an obviously fatal head injury might benefit more from repair of the lesion because this will allow blood pressure control to be liberalized, permitting improved cerebral perfusion pressure. Thus it might be more appropriate to repair or stent injuries in these patients.

The risk of rupture appears to be markedly reduced by 7 to 10 days after injury. ${ }^{18}$ Some lesions, if pressure can be critically controlled, might heal particularly small intimal defects. ${ }^{36,37}$ As long as serial follow-up is performed and strict blood pressure control is possible, with no evidence of growth of the lesion in the first week, these can be safely followed rather than operated on. Persistent aneurysm formation can be managed electively after this time or when the patient's condition permits.

Endovascular stent graft techniques continue to evolve. They are particularly exciting as a potential therapy in patients who have contraindications to open repair but are not good candidates for medical management and temporization, either because of the size of the tear or closed head injury. Initial experience was with hand-sewn devices, but with increasing availability of commercial stents designed for the thoracic aorta, this will become a more frequent option. ${ }^{38-42}$ However, not all patients will be anatomically suitable for stent grafts, and the long-term outcomes have yet to be determined. Thus there will be, for the foreseeable future, an important role for operative and nonoperative management.

\section{Conclusion}

We have used a previously published series of aortic transaction cases as a reference point to study the effect of a wide number of changes in the management and presentation of these injuries over a decade. Clearly this has inherent flaws because a case-to-case comparison would be more accurate, but we believe it is useful nonetheless to review these changes. 
There has been a marked reduction overall in mortality. The primary reason for this appears to be the increased use of restraints in motor vehicle crashes, with the result that patients present with a lesser degree of injury, both aortic and systemic. This allows more flexibility in managing these patients. One aspect of this flexibility is the recognition that in selected cases outcome can actually be improved by specific delay in operative intervention. This must be coupled with early institution of $\beta$-blockers when the diagnosis is suspected. Operatively, there have been some consistent changes that affect outcome as well. Following the lead of the initial Harborview investigators and many other centers, mechanical circulatory support is regularly used, with a marked reduction in paralysis and end-organ failure and a reduction, although not statistically significant, in operative mortality. Finally, endovascular stent grafts offer a less morbid procedure that can be performed in patients who cannot undergo operative repair but in whom delay is judged to be too risky or contraindicated. As newer devices are studied, this might very well ultimately become the primary treatment of choice at all centers.

\section{References}

1. Eddy AC, Rusch VW, Marchioro T, Ashbaugh D, Verrier ED, Dillard D. Treatment of traumatic rupture of the thoracic aorta. A 15-year experience. Arch Surg. 1990;125:1351-6.

2. Forbes AD, Ashbaugh DG. Mechanical circulatory support during repair of thoracic aortic injuries improves morbidity and prevents spinal cord injury. Arch Surg. 1994;129:494-8.

3. Downing SW, Cardarelli MG, Sperling J, et al. Heparinless partial cardiopulmonary bypass for the repair of aortic trauma. $J$ Thorac Cardiovasc Surg. 2000;120:1104-11.

4. Arajarvi E, Santavirta S. Chest injuries sustained in severe traffic accidents by seatbelt wearers. J Trauma. 1989;29:37-41.

5. Arajarvi E, Santavirta S, Tolonen J. Aortic ruptures in seat belt wearers. J Thorac Cardiovasc Surg. 1989;98:355-61.

6. Mattox KL, Wall MJ Jr. Historical review of blunt injury to the thoracic aorta. Chest Surg Clin N Am. 2000;10:167-82.

7. Pate JW. Is traumatic rupture of the aorta misunderstood? Ann Thorac Surg. 1994;57:530-1.

8. Fabian TC, Davis KA, Gavant ML, et al. Prospective study of blunt aortic injury: helical CT is diagnostic and antihypertensive therapy reduces rupture. Ann Surg. 1998;227:666-77.

9. Mattox KL. Red River anthology. J Trauma. 1997;42:353-68.

10. Dunham MB, Zygun D, Petrasek P, Kortbeek JB, Karmy-Jones R, Moore RD. Endovascular stent grafts for acute blunt aortic injury. J Trauma. 2004;56:1173-8.

11. Karmy-Jones R, Hoffer E, Meissner MH, Nicholls S, Mattos M. Endovascular stent grafts and aortic rupture: a case series. $J$ Trauma. 2003;55:805-10.

12. Carter Y, Meissner M, Bulger E, et al. Anatomical considerations in the surgical management of blunt thoracic aortic injury. J Vasc Surg. 2001;34:628-33

13. Karmy-Jones R, Carter YM, Nathens A, et al. Impact of presenting physiology and associated injuries on outcome following traumatic rupture of the thoracic aorta. Am Surg. 2001;67:61-6.

14. Karmy-Jones R, Carter Y, Meissner M, Mulligan MS. Choice of venous cannulation for bypass during repair of traumatic rupture of the aorta. Ann Thorac Surg. 2001;71:39-42.

15. Maggisano R, Nathens A, Alexandrova NA, et al. Traumatic rupture of the thoracic aorta: should one always operate immediately? Ann Vasc Surg. 1995;9:44-52.
16. Parmley L, Mattingly T, Manion W, Jahnke E. Nonpenetrating traumatic injury of the aorta. Circulation. 1958;17:1086-101.

17. Lee RB, Stahlman GC, Sharp KW. Treatment priorities in patients with traumatic rupture of the thoracic aorta. Am Surg. 1992;58:37-43.

18. Holmes JHt, Bloch RD, Hall RA, Carter YM, Karmy-Jones RC. Natural history of traumatic rupture of the thoracic aorta managed nonoperatively: a longitudinal analysis. Ann Thorac Surg. 2002;73:1149-54.

19. Fabian TC, Richardson JD, Croce MA, et al. Prospective study of blunt aortic injury: Multicenter Trial of the American Association for the Surgery of Trauma. J Trauma. 1997;42:374-83.

20. Burkhart HM, Gomez GA, Jacobson LE, Pless JE, Broadie TA. Fatal blunt aortic injuries: a review of 242 autopsy cases. J Trauma. 2001; 50:113-5.

21. Pillgram-Larsen J, Geiran O. [Air bags influence the pattern of injury in severe thoracic trauma]. Tidsskr Nor Laegeforen. 1997;117:2437-9.

22. Dunn JA, Williams MG. Occult ascending aortic rupture in the presence of an air bag. Ann Thorac Surg. 1996;62:577-8.

23. Marnocha KE, Maglinte DD. Plain-film criteria for excluding aortic rupture in blunt chest trauma. AJR Am J Roentgenol. 1985;144:19-21.

24. Dyer DS, Moore EE, Ilke DN, et al. Thoracic aortic injury: how predictive is mechanism and is chest computed tomography a reliable screening tool? A prospective study of 1,561 patients. J Trauma. 2000;48:673-83.

25. Downing SW, Sperling JS, Mirvis SE, et al. Experience with spiral computed tomography as the sole diagnostic method for traumatic aortic rupture. Ann Thorac Surg. 2001;72:495-502.

26. Karmy-Jones R, DuBose R, King S. Traumatic rupture of the innominate artery. Eur J Cardiothorac Surg. 2003;23:782-7.

27. Chen MY, Regan JD, D'Amore MJ, Routh WD, Meredith JW, Dyer $\mathrm{RB}$. Role of angiography in the detection of aortic branch vessel injury after blunt thoracic trauma. J Trauma. 2001;51:1166-72.

28. Ahrar K, Smith DC, Bansal RC, Razzouk A, Catalano RD. Angiography in blunt thoracic aortic injury. J Trauma. 1997;42:665-9.

29. Razzouk AJ, Gundry SR, Wang N, del Rio MJ, Varnell D, Bailey LL. Repair of traumatic aortic rupture: a 25-year experience. Arch Surg. 2000;135:913-9.

30. Schmidt CA, Wood MN, Razzouk AJ, Killeen JD, Gan KA. Primary repair of traumatic aortic rupture: a preferred approach. $J$ Trauma. 1992;32:588-92.

31. Akins CW, Buckley MJ, Daggett W, McIlduff JB, Austen WG. Acute traumatic disruption of the thoracic aorta: a ten-year experience. Ann Thorac Surg. 1981;31:305-9.

32. Pate JW, Gavant ML, Weiman DS, Fabian TC. Traumatic rupture of the aortic isthmus: program of selective management. World J Surg. 1999;23:59-63.

33. Warren RL, Akins CW, Conn AK, Hilgenberg AD, McCabe CJ. Acute traumatic disruption of the thoracic aorta: emergency department management. Ann Emerg Med. 1992;21:391-6.

34. Pierangeli A, Turinetto B, Galli R, Caldarera L, Fattori R, Gavelli G. Delayed treatment of isthmic aortic rupture. Cardiovasc Surg. 2000;8:280-3.

35. Feliciano DV. Trauma to the aorta and major vessels. Chest Surg Clin N Am. 1997;7:305-23.

36. Kepros J, Angood P, Jaffe CC, Rabinovici R. Aortic intimal injuries from blunt trauma: resolution profile in nonoperative management. J Trauma. 2002;52:475-8.

37. Malhotra AK, Fabian TC, Croce MA, Weiman DS, Gavant ML, Pate JW. Minimal aortic injury: a lesion associated with advancing diagnostic techniques. J Trauma. 2001;51:1042-8.

38. Kato N, Dake MD, Miller DC, et al. Traumatic thoracic aortic aneurysm treatment with endovascular stent-grafts. Radiology. 1997;205:657-62.

39. Kato N, Hirano T, Ishida M, et al. Acute and contained rupture of the descending thoracic aorta: treatment with endovascular stent grafts. J Vasc Surg. 2003;37:100-5.

40. Dake MD, Miller DC, Semba CP, Mitchell RS, Walker PJ, Liddell RP. Transluminal placement of endovascular stent-grafts for the treatment of descending thoracic aortic aneurysms. N Engl J Med. 1994;331: 1729-34.

41. Orford VP, Atkinson NR, Thompson K, et al. Blunt traumatic aortic transection: the endovascular experience. Ann Thorac Surg. 2003;75:106-112.

42. Lachat M, Pfammatter T, Witzke $\mathrm{H}$, et al. Acute traumatic aortic rupture: early stent-graft repair. Eur J Cardiothorac Surg. 2002;21:959-63. 